\title{
Sensitivity estimations for cloud droplet formation in the vicinity of the high-alpine research station Jungfraujoch ( 3580 m a.s.l.)
}

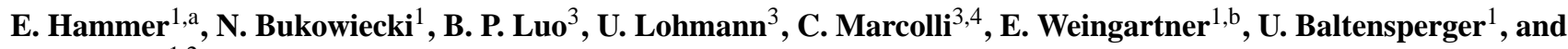 \\ C. R. Hoyle ${ }^{1,2}$ \\ ${ }^{1}$ Laboratory of Atmospheric Chemistry, Paul Scherrer Institute, 5232 Villigen PSI, Switzerland \\ ${ }^{2}$ Swiss Federal Institute for Forest Snow and Landscape Research (WSL)-Institute for Snow and Avalanche Research (SLF), \\ Davos, Switzerland \\ ${ }^{3}$ Institute for Atmospheric and Climate Science, ETH Zurich, 8092 Zurich, Switzerland \\ ${ }^{4}$ Marcolli Chemistry and Physics Consulting GmbH, 8092 Zurich, Switzerland \\ ${ }^{a}$ now at: Grolimund + partner AG - environmental engineering, 3018 Bern, Switzerland \\ ${ }^{b}$ now at: Institute for Aerosol and Sensor Technology, University of Applied Sciences and Arts Northwestern Switzerland, \\ Switzerland
}

Correspondence to: C. R. Hoyle (christopher.hoyle@env.ethz.ch)

Received: 19 August 2014 - Published in Atmos. Chem. Phys. Discuss.: 17 October 2014

Revised: 9 September 2015 - Accepted: 9 September 2015 - Published: 18 September 2015

\begin{abstract}
Aerosol radiative forcing estimates suffer from large uncertainties as a result of insufficient understanding of aerosol-cloud interactions. The main source of these uncertainties is dynamical processes such as turbulence and entrainment but also key aerosol parameters such as aerosol number concentration and size distribution, and to a much lesser extent, the composition. From June to August 2011 a Cloud and Aerosol Characterization Experiment (CLACE2011) was performed at the high-alpine research station Jungfraujoch (Switzerland, $3580 \mathrm{~m}$ a.s.l.) focusing on the activation of aerosol to form liquid-phase clouds (in the cloud base temperature range of -8 to $5^{\circ} \mathrm{C}$ ). With a box model the sensitivity of the effective peak supersaturation $\left(\mathrm{SS}_{\text {peak }}\right)$, an important parameter for cloud activation, to key aerosol and dynamical parameters was investigated. The updraft velocity, which defines the cooling rate of an air parcel, was found to have the greatest influence on $\mathrm{SS}_{\text {peak }}$. Smallscale variations in the cooling rate with large amplitudes can significantly alter CCN activation. Thus, an accurate knowledge of the air parcel history is required to estimate $\mathrm{SS}_{\text {peak }}$. The results show that the cloud base updraft velocities estimated from the horizontal wind measurements made at the Jungfraujoch can be divided by a factor of approximately 4 to get the updraft velocity required for the model to reproduce the observed $\mathrm{SS}_{\text {peak }}$. The aerosol number concentration and
\end{abstract}

hygroscopic properties were found to be less important than the aerosol size in determining $\mathrm{SS}_{\text {peak }}$. Furthermore turbulence is found to have a maximum influence when $\mathrm{SS}_{\text {peak }}$ is between approximately 0.2 and $0.4 \%$. Simulating the smallscale fluctuations with several amplitudes, frequencies and phases, revealed that independently of the amplitude, the effect of the frequency on $\mathrm{SS}_{\text {peak }}$ shows a maximum at $0.46 \mathrm{~Hz}$ (median over all phases) and at higher frequencies, the maximum $\mathrm{SS}_{\text {peak }}$ decreases again.

\section{Introduction}

The interactions between aerosols and clouds are the largest contributors to uncertainty in the calculation of aerosol radiative forcing (Boucher et al., 2013). Aerosols with a certain size, shape and chemical composition are able to form a cloud droplet, if they are exposed to air which is supersaturated with respect to water vapour. Particles that are able to activate and become cloud droplets are called cloud condensation nuclei $(\mathrm{CCN})$. The number concentration of $\mathrm{CCN}$ is determined by the aerosol number size distribution, the hygroscopic properties of the aerosol and the supersaturation in the surrounding air. Thus, to address the aerosol-cloud interaction processes in detail, all these properties need to be 
known. However, present climate models are not capable of representing these aerosol properties in the required detail. Thus, compromises and assumptions that accurately address the most important aerosol effects within the constraints of application are required (Cherian et al., 2014; Dufresne et al., 2013; Levy et al., 2013). It has been pointed out by Boucher et al. (2013) and Spichtinger and Cziczo (2008) that the main uncertainties in the aerosol radiative forcing are due to aerosol-cloud interaction dynamical factors such as turbulent strength and entrainment controlling the cloud condensation rate, and the key aerosol parameters such as aerosol number concentration and size distribution, and to a much lesser extent, the composition. The interplay of dynamics versus effects purely attributed to aerosols remains highly uncertain. Thus, in this study the influence of the variation of the turbelent strength and the updraft velocity on the cloud activation is investigated using a cloud parcel model.

One of the properties that can be used to characterize the $\mathrm{CCN}$ activity of an aerosol particle is the critical supersaturation, i.e. the lowest supersaturation at which the particle is activated to a cloud droplet. The critical supersaturation depends on the particle size and chemical composition and is described by Köhler theory (Köhler, 1936). Whether a particle is able to act as a CCN in the atmosphere depends, aside from the particle's chemical and physical properties, on the supersaturation of water vapour. As an air parcel rises, it cools and may become supersaturated. Those particles with a critical supersaturation at or below the supersaturation in the air parcel will activate to form cloud droplets. The highest supersaturation that a particle experiences for a sufficiently long time to grow to a stable cloud droplet is defined as the effective peak supersaturation $\left(\mathrm{SS}_{\text {peak }}\right.$; Hammer et al., 2014a) and this value is important as it determines the minimum activation diameter in a population of particles, and thus the number of particles which activate to form cloud droplets. Small-scale fluctuations in vertical velocity can alter the path of an air parcel and thereby also the corresponding $\mathrm{SS}_{\text {peak }}$, which is dependent on the cooling rate of the air parcel.

The influence of physical and chemical quantities on the sensitivity of the number and size of cloud droplets to smallscale fluctuations in temperature and saturation has been the subject of model studies for some time.

A three-dimensional model was used by Clark and Hall (1979) to examine the effect of fluctuations in supersaturation on the droplet size distribution evolution. They suggest that the observed broadening in the droplet size distribution above cloud base in cumulus clouds cannot be fully reproduced by the addition of fluctuations to a Lagrangian model, as this ignores spatial correlations between population or thermodynamic characteristics. However they also performed Lagrangian simulations for comparison with their 3-D modelling results, and found that these reproduce a lower bound to the population broadening caused by turbulence.
Fluctuations in saturation ratio were also investigated with a stochastic model by Kulmala et al. (1997), who pointed out that under conditions that are, on average, sub-saturated, fluctuations may lead to the activation of aerosol, and that above saturation, variation in saturation ratio may lead to accelerated growth of droplets.

At higher particle number densities, the number of activated aerosol particles has been found to become more sensitive to the updraft velocity. For example, Feingold et al. (2003) applied an adiabatic parcel model and found that in non-precipitating stratocumulus cloud, at higher aerosol number densities (above a number corresponding to an extinction of approximately $0.008 \mathrm{~km}^{-1}$ in their study), the updraft velocity begins to have an influence on the droplet effective radius, as more aerosol is activated and the available condensable water is shared among more growing droplets. Similarly, an adiabatic parcel model was used by Chuang (2006) to show that aerosol activation is sensitive to the mass accommodation coefficient below values of approximately $0.1-0.001$, and that the sensitivity to updraft velocity is greater under polluted conditions than under conditions with low aerosol number concentrations.

With regard to the chemical composition of the aerosol, Lance et al. (2004) used a cloud parcel model to show that the presence of organic surfactants enhances the sensitivity of the modelled droplet concentration to vertical wind velocity, increasing the number of droplets. Under polluted conditions, this effect was determined to be of the same scale as the influence of updraft velocity. Likewise, in the study of Partridge et al. (2012), an adiabatic cloud parcel model was used to show that under clean conditions, the number and size of aerosol in the accumulation mode was important in determining the number of cloud droplets, however under polluted conditions, aerosol activation was more sensitive to chemical composition. Also, the sensitivity of the cloud droplet formation to aerosol chemical composition was found to increase when the updraft was reduced. Under less-polluted conditions, using data from a non-urban site, Dusek et al. (2010) have shown that the number of activated aerosol mainly depends on the details of the aerosol size distribution and not the chemical composition.

Several studies also exist which present good predictions of cloud droplet numbers by empirical equations based on the number of aerosols larger than a certain size. These studies imply that at least for stratus clouds, the aerosol number is the most important factor in determining the activated fraction and the number of cloud droplets formed (e.g. Raga and Jonas, 1993; Jones, 1994; Martin et al., 1994).

Ditas et al. (2012) derived the fluctuations of supersaturation in marine stratocumulus, based on observational data, finding a peak to peak supersaturation fluctuation in the range of $1.5 \%$. Ranges of supersaturations were also measured by Politovich and Cooper (1988), finding standard deviations in the $10 \mathrm{~m}$ average supersaturation of around $0.1-0.4 \%$ depending on the amount of entrainment. They suggest that the 
range of the observed droplet size distributions may be accounted for by the variation in supersaturation.

The present study builds on the work of Hammer et al. (2014a), which showed that there is a strong link between $\mathrm{SS}_{\text {peak }}$ and the updraft velocity. Additionally, it was shown that the physical properties (number concentration and size) of the aerosol possibly also have a non-negligible influence on $\mathrm{SS}_{\text {peak }}$. However, the study was not able to shed light into which extent each parameter contributed to $\mathrm{SS}_{\text {peak }}$. In here a sensitivity study was performed to gain more knowledge of the contribution of different physical and chemical aerosol parameters as well as the dynamical history of the air parcel to $\mathrm{SS}_{\text {peak }}$. This was done for a dedicated measurement campaign (CLACE2011; described in Sect. 2). Although only results from the campaign performed in 2011 are shown, all results shown in Sects. 3.1 and 3.2 are also applicable to the earlier campaign performed in 2010 as the chemical and physical properties of the aerosol, and the meteorological conditions encountered during the campaign were similar in 2010 and 2011 (Hammer et al., 2014a).

In the next section, the methods used to collect observation data and calculate the derived quantities are described. A description of the model is also provided. The results of the study are discussed in Sect. 3 and conclusions are presented in Sect. 4. An overview of all the notation used in this manuscript, grouped into calculated, measured and modelled parameters is given in Table 1.

\section{Methods}

\subsection{Observational data}

Measurements of aerosol and cloud properties were performed at the high-alpine site Jungfraujoch (3580 ma.s.1.) in Switzerland during summer 2011. This intensive measurement campaign was carried out within the framework of a CLoud and Aerosol Characterization Experiment (CLACE2011) campaign. The main focus of the campaign was to investigate the physical, chemical and optical properties of aerosols as well as the interaction of the aerosol particles with clouds, for a better quantification of the radiative forcing due to aerosol-radiation interactions (RFari) and the radiative forcing due to aerosol-cloud interactions (RFaci). These measurements provide the basis for the modelling study in here.

Due to the topography around the Jungfraujoch (JFJ) mainly northwest (NW) and southeast (SE) wind directions are observed at the site. The topography approaching from the NW differs from that on the SE side as can be seen in Fig. 1. To the SE, the Great Aletsch glacier declines gradually from the JFJ ( $1500 \mathrm{~m}$ of altitude decrease over $18 \mathrm{~km}$ ) while the NW side drops steeply, descending $1500 \mathrm{~m}$ over a horizontal distance of $4800 \mathrm{~m}$ (Ketterer et al., 2014).

\subsubsection{Measurement setup}

A number of quantities measured at the JFJ were either used as model input directly, or were used to calculate model input parameters. These included the aerosol size distribution, the temperature and pressure, wind speed and direction, and the total water content of the air. For sampling the aerosols and the hydrometeors on JFJ, an interstitial and a total inlet were installed on the roof of the laboratory. The interstitial inlet sampled only the non-activated particles by a size discriminator to remove droplets larger than $2 \mu \mathrm{m}$ in aerodynamic diameter. In the laboratory the aerosol was dried to $\mathrm{RH}<10 \%$ as it was heated to room temperature (typically 20 to $30^{\circ} \mathrm{C}$ ). The total inlet sampled the hydrometeors as well as the interstitial particles, i.e. all particles. The condensed water of the hydrometeors and the aerosol particles was evaporated via heating the top part of the total inlet to approximately $20^{\circ} \mathrm{C}$. Thus, all dried aerosol particles (non-activated aerosols and the residuals of the cloud droplets) reached the laboratory. The difference between the number concentration measured behind the total inlet minus the number concentration measured behind the interstitial inlet corresponds to the number of cloud residuals, i.e. the number of particles that have been activated to cloud droplets. Downstream of the inlets, two scanning mobility particle sizers (SMPS) measured the total and the interstitial dry particle number concentration, respectively. Additionally, a cloud condensation nuclei counter (CCNC; DMT CCNC-100, described by Roberts and Nenes, 2005) measured the polydisperse $C C N$ number concentration at eight defined supersaturations (SS) behind the total inlet. Combining these measurements with the total dry particle number size distributions, measured with the SMPS behind the total inlet, the hygroscopicity parameter $(\kappa$; Petters and Kreidenweis, 2007) was inferred (Hammer et al., 2014a).

The 3-D wind speed vector at the JFJ with a time resolution of $20 \mathrm{~Hz}$ was measured with an ultrasonic anemometer (Metek USA-1). This instrument was installed on a $3 \mathrm{~m}$ pole pointing away from the JFJ building to reduce the influence of the building on the measured wind fields, although this influence could not be totally eliminated. Therefore, the wind direction and horizontal wind speed data of the ultrasonic anemometer were not further used in this study. Nevertheless, the high-time resolved vertical wind speed measured by the ultrasonic anemometer is still expected to provide information on the small-scale fluctuations of the air mass.

The horizontal wind direction was obtained with the Rosemount pitot tube anemometer. This instrument is mounted at the top of a $10 \mathrm{~m}$ mast located at around $75 \mathrm{~m}$ away from the ultrasonic anemometer. The measurements were performed as part of the SwissMetNet network of MeteoSwiss together with temperature and pressure measurements continuously obtained at the JFJ. The temperature is measured with a thermo-hygrometer Thygan VTP-37 (Meteolabor AG).

Cloud presence and LWC were measured with a particle volume monitor (PVM-100; Gerber, 1991). 
Table 1. List of important symbols.

\begin{tabular}{|c|c|}
\hline Parameter & Notation \\
\hline \multicolumn{2}{|c|}{ General parameters } \\
\hline SS & supersaturation \\
\hline $\mathrm{SS}_{\text {peak }}$ & effective peak supersaturation (Hammer et al., 2014a) \\
\hline $\mathrm{SS}_{\text {crit }}$ & critical supersaturation (Köhler, 1936) \\
\hline$w$ & updraft velocity \\
\hline \multicolumn{2}{|c|}{ Measured parameters } \\
\hline $\mathrm{w}_{\text {act }}^{\text {meas }}$ & measured updraft velocity \\
\hline \multicolumn{2}{|c|}{ Estimated parameters } \\
\hline $\mathrm{SS}_{\text {peak }}^{\text {estim }}$ & estimated effective peak supersaturation derived from measurements (see Sect. 2.1.4) \\
\hline$w_{\text {act }}^{\text {estim }}$ & estimated updraft velocity derived from measurements and topography (see Sect. 2.1.3) \\
\hline \multicolumn{2}{|c|}{ Modelled parameters } \\
\hline $\mathrm{SS}_{\text {peak }}^{\text {mod }}$ & modelled effective peak supersaturation \\
\hline $\mathrm{SS}_{\text {peak }}^{\text {ref }}$ & effective peak supersaturation obtained from the reference model simulation \\
\hline $\mathrm{SS}_{\bmod }^{\max }$ & maximum relative water vapour pressure between the model initialization point and the JFJ \\
\hline $\mathrm{w}_{\text {act }}^{\bmod }$ & modelled updraft velocity \\
\hline$w_{\bmod }^{\text {divX }}$ & modelled updraft velocity divided by $X$ \\
\hline$w_{\text {mod }}^{\text {mulx }}$ & modelled updraft velocity multiplied by $X$ \\
\hline $\mathrm{SS}_{\text {peak }}^{\text {fluc }}$ & modelled effective peak supersaturation applying the real-time fluctuations \\
\hline $\mathrm{SS}_{\text {peak }}^{\text {fluc,sin }}$ & modelled effective peak supersaturation with a sinus function \\
\hline
\end{tabular}

\subsubsection{Defined cloud periods}

Cloud periods that exhibited evidence of substantial entrainment or mixing were not included in the analysis. Such clouds were detected by analysing the activated fraction of the aerosol particles as a function of aerosol size. Periods where the largest size bins were not at least $90 \%$ activated were excluded. This is the same procedure to that used by Hammer et al. (2014a).

Here, only clouds observed at the JFJ under NW wind directions are considered. The clouds formed under NW wind conditions are mostly found to be formed locally by rapid updrafts, in contrast to the clouds formed under southerly wind conditions, which are often stratus, that have been advected from further away. There are also rather few measurement points when SE wind was present, as the prevailing wind direction at the JFJ is from the NW.

\subsubsection{Estimation of the updraft velocity at the cloud base}

It is not feasible to measure the updraft velocity at the point of aerosol activation at the JFJ. Thus, an estimate of the updraft velocity at the cloud base $\left(w_{\text {act }}^{\text {estim }}\right)$ was inferred from the horizontal wind speed at the JFJ, as measured by the Rosemount pitot tube anemometer by making the following assumptions: (1) the air approaching the JFJ research sta- tion strictly followed the terrain. (2) Neither horizontal convergence nor divergence of the flow lines occurred between cloud base and the JFJ. Thus, the horizontal wind speed component stays the same between cloud base and the JFJ. With these assumptions, $w_{\text {act }}^{\text {estim }}$ is obtained from the horizontal wind speed measured at the JFJ $\left(v_{\mathrm{JFJ}}^{\mathrm{h}}\right)$ :

$w_{\mathrm{act}}^{\mathrm{estim}}=\tan (\alpha) v_{\mathrm{JFJ}}^{\mathrm{h}}$,

where $\alpha$ denotes the inclination angle of the flow lines at cloud base. According to the topography software "Atlas der Schweiz 3.0" from Swisstopo and ETH Zurich, the terrain has a mean inclination of $\alpha \approx 46^{\circ}$ over the last $700 \mathrm{~m}$ altitude difference before reaching the JFJ for northwesterly advection, therefore this angle was used in the updraft estimation (Hammer et al., 2014a).

\subsubsection{The effective peak supersaturation}

The cooling of an air parcel below its dew point temperature results in the formation of a cloud. According to Köhler theory (Köhler, 1936), the equilibrium saturation vapour pressure $\left(S_{\text {eq }}\right)$ over a solution droplet is described considering the Raoult (solute) and Kelvin laws. The critical supersaturation $\left(\mathrm{SS}_{\text {crit }}\right)$ of a particle with a certain size and composition $(\kappa$; Petters and Kreidenweis, 2007) defines the point of activation from particle to cloud droplet. Therefore, all particles 

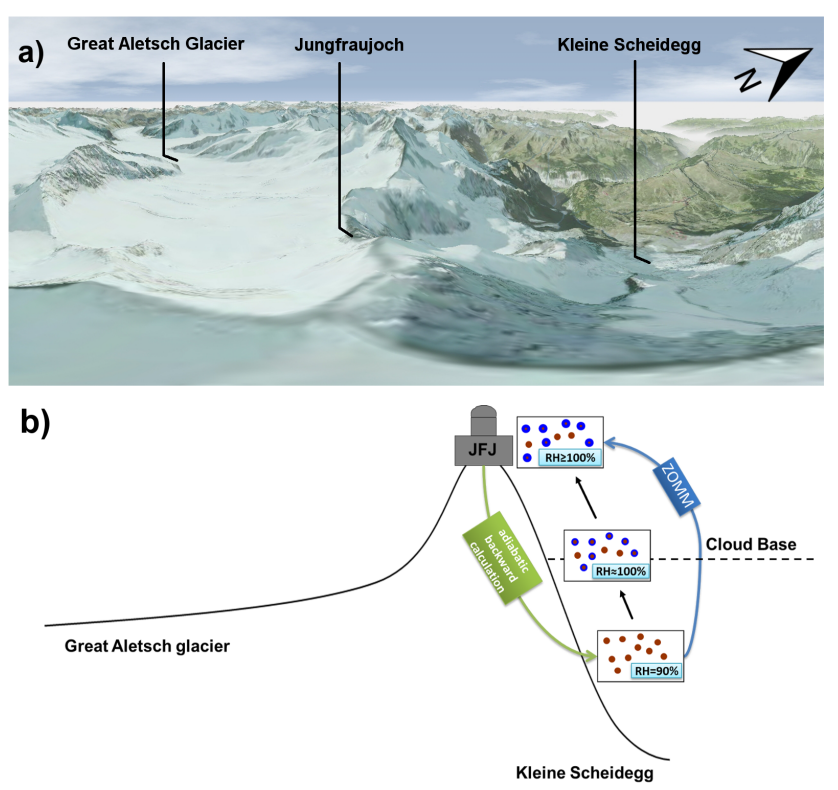

Figure 1. In (a) a panorama picture is shown to give an overview of the surroundings of the Jungfraujoch. The topography is shown in a sketch (b) along with the subsaturated conditions, conditions at the cloud base and at the Jungfraujoch. The green arrow shows the adiabatic backward calculations for the conditions at subsaturated conditions (initialization point of ZOMM; $\mathrm{RH}=90 \%$ ) with the measurements performed at the Jungfraujoch. The blue arrow shows the direction from the initialization point of the model until the end state of the simulation, which is at the Jungfraujoch. Brown dots indicate aerosol particles, blue dots cloud droplets.

in an air parcel having a $\mathrm{SS}_{\text {crit }}$ smaller than $\mathrm{SS}_{\text {peak }}$ are able to activate and grow to cloud droplets. In the box model the $S_{\text {eq }}$ is calculated for each time step along the temperature and pressure on the air parcel trajectory. The maximum relative water vapour pressure between the model initialization point and the JFJ is expressed as $\mathrm{SS}_{\max }^{\bmod }$. The simulated effective peak supersaturation, $\mathrm{SS}_{\text {peak }}^{\text {mod }}$, however is below $\mathrm{SS}_{\max }^{\bmod }$. $\mathrm{SS}_{\text {peak }}^{\text {mod }}$ was obtained by finding the highest water vapour saturation which leads to droplets larger than $2 \mu \mathrm{m}$ in diameter. In earlier studies it was found that a diameter of $2 \mu \mathrm{m}$ is a good threshold distinguishing the hygroscopically grown particles from cloud droplets (Jurányi et al., 2011; Henning et al., 2002).

It is important to note that in Hammer et al. (2014a) the definition of the $\mathrm{SS}_{\text {peak }}^{\mathrm{mod}}$ simply was the "highest SS reached along the trajectory". The new definition described above is needed for investigating the small-scale fluctuations described in Sect. 3.3.1. The comparison of $\mathrm{SS}_{\text {peak }}^{\text {mod }}$ obtained by the two definitions, respectively, was within $10 \%$.

The $\mathrm{SS}_{\text {peak }}$ was retrieved as follows: (1) the activation threshold diameter was determined from the measurements of the total and interstitial number size distributions; (2) the aerosol hygroscopicity was obtained from the simultaneous $\mathrm{CCNC}$ measurements and (3) the activation threshold diam- eter was combined with the aerosol hygroscopicity to infer the effective peak supersaturation. A relative uncertainty of about $\pm 30 \%$ was estimated for $\mathrm{SS}_{\text {peak }}$. A detailed description of how the $\mathrm{SS}_{\text {peak }}$ was estimated from the measurements performed at the JFJ can be found in Hammer et al. (2014a).

\subsection{Box model description (ZOMM)}

The Zurich optical and microphysical model (ZOMM) was used in this study to simulate the effect of aerosol properties and atmospheric dynamics on liquid cloud formation (ice formation was not simulated). ZOMM is a box model which calculates the evolution of an initial aerosol distribution along a temperature and pressure trajectory. A basic description of ZOMM can be found in Luo et al. (2003) and Hoyle et al. $(2005,2013)$. The model is available on request via the following e-mail: beiping.luo@env.ethz.ch.

For the initialization of the model, the cloud periods detected at the JFJ were divided into 6-min periods. The 6-min periods were chosen according to the instrument with the lowest time resolution which is the SMPS instrument measuring the dry particle size distribution. Therefore, all aerosol and cloud properties described in this study are given in 6min averages. The temperature range of the observed clouds was from -8 to $5^{\circ} \mathrm{C}$.

It was important to know the altitude of cloud base. The cloud base altitude was inferred from the liquid water content (LWC) of the cloud observed at the JFJ assuming an adiabatic rise of the air parcel before cloud formation. It is assumed that the total water content is preserved, since water removal due to precipitation was negligible (Hammer et al., 2014a). Assuming all the water is in the vapour phase, the dew point temperature was calculated via the ideal gas law and the Clausius-Clapeyron equation (Goff and Gratch, 1946). Via the hypsometric equation, the cloud base can be determined by iteratively lowering the altitude. The cloud base was defined as the point where the water partial pressure (assuming all water is in the gas phase) is equal to the saturation vapour pressure over liquid water (corrected for the pressure difference between the cloud base and the JFJ). A detailed description can be found in Hammer et al. (2014a).

The model was initialized with an aerosol size distribution, consisting of aerosol number concentrations in 100 size bins. The size distributions were taken from the SMPS measurements at the total inlet, and therefore include both activated and interstitial aerosol. As ZOMM is a box model, mixing and sedimentation processes are not accounted for, and the total water content of an air parcel is conserved during the simulation. The total water contents used in the simulations were determined from the sum of the gas and liquid phase water measured at the JFJ. To initialize the model under clearly subsaturated conditions, the temperature, and the corresponding pressure on the air parcel trajectory was calculated at $\mathrm{RH} \approx 90 \%$ to the cloud base of $\mathrm{RH}=100 \%$ assuming a dry adiabatic lapse rate of $\Gamma_{\text {dry }}=0.98 \mathrm{~K}(100 \mathrm{~m})^{-1}$. 
The calculation of the temperature and the corresponding pressure on the air parcel trajectory from the cloud base to the JFJ was done assuming a wet adiabatic lapse rate of $\Gamma_{\text {wet }}=0.65 \mathrm{~K}(100 \mathrm{~m})^{-1}$. Implicit in this initialization is the assumption that the dry aerosol size distribution observed at the JFJ is the same as that which was present at the cloud base. As it is not feasible to measure the aerosol size distributions below the cloud base at the JFJ, this assumption cannot be tested. However in this study the analysis is not performed on single trajectories, rather the results of the simulations are examined together, therefore the variability of the size distributions observed at the JFJ should capture the variability of the size distributions below the cloud base.

The aerosol size observed in a single SMPS measurement has an uncertainty of about $10 \%$ Wiedersohler et al. (2012), however the input distributions used in the basic model simulations consist of median size distributions taken over the CLACE2011 campaign. The bin resolution used in the model is the same as that measured by the SMPS. Any uncertainties in the model calculation resulting from the resolution of the bin sizes or the aerosol size distribution would be much smaller than the differences in simulated peak supersaturation caused by varying the number and size of the aerosols, as is done in Fig. 6.

The equilibrium water content of the aerosol (i.e. the hygroscopic growth) is calculated according to the $\kappa$-Köhler parametrization of (Petters and Kreidenweis, 2007)

$S(D, \kappa)=\frac{D^{3}-D_{\mathrm{dry}}^{3}}{D^{3}-D_{\mathrm{dry}}^{3}(1-\kappa)} \exp \left(\frac{4 \sigma_{\mathrm{s} / \mathrm{a}} M_{\mathrm{w}}}{R T \rho_{\mathrm{w}} D}\right)$,

where $D$ is the droplet diameter, $D_{\text {dry }}$ the dry diameter, $\sigma_{\mathrm{s} / \mathrm{a}}$ the surface tension of the solution/air interface $\left(0.072 \mathrm{Jm}^{-2}\right.$, following Petters and Kreidenweis, 2007), $M_{\mathrm{w}}$ the molar mass of water, $R$ the ideal gas constant, $T$ the prevailing air temperature and $\rho_{\mathrm{w}}$ the density of water. At $S \leq 0.99$ with respect to liquid water, the aerosol is assumed to be in equilibrium with the gas phase and the model time step is $1 \mathrm{sec}$. At $S>0.99$, Eq. (2) is used to calculate the equilibrium vapour pressure over the aqueous phase droplets, and the flux of water between the droplets and the gas phase is calculated, accounting for gas phase diffusion as well as the Kelvin effect. Based on the calculated flux, the model time step is determined, such that the water content of the droplet can change by no more than $2 \%$ per time step, enabling the model to resolve even high-frequency fluctuations.

The new radius of each size bin is calculated, and the bins are allowed to evolve independently in radius space, i.e. they are not constrained to a particular distribution shape.

The simulation follows the time series of temperature and pressure values which is given as input, and the simulation ends once the conditions observed at the JFJ are reached. In this way, the number of activated droplets and the effective peak supersaturation predicted by the model can be compared with the values determined from the JFJ observational

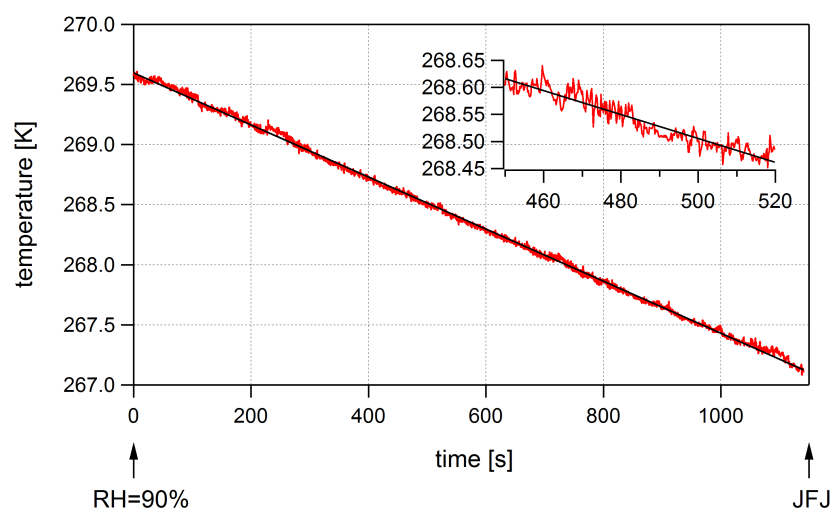

Figure 2. For the model run \#516, performed for conditions observed on 8 August 2011 18:20 UTC, the temperature trajectory is shown with the added small-scale temperature fluctuation $\left(T_{\text {turb }}\right)$ retrieved from the sonic anemometer measurements (see detailed description in Sect. 2.3.1). The inset shows the trajectory on a smaller scale for a more quantitative view of the small-scale temperature fluctuations.

data. The modelled peak supersaturation is defined based on the point of activation of the smallest aerosol (i.e. the highest supersaturation reached which resulted in droplet activation), not on the final droplet size.

\subsection{Investigated parameters}

\subsubsection{Simulated small-scale temperature fluctuations}

To investigate the influence of the small-scale fluctuations of $\mathrm{SS}_{\text {peak }}$ on the temperature ( $\left.T_{\text {turb }}\right)$ and pressure along the air parcel trajectory from the initialization point to the JFJ at time $(t)$, the $20 \mathrm{~Hz}$ time-resolved updraft velocities measured by the sonic anemometer $\left(w_{\text {act }}^{\text {meas }}\right)$ were applied to the linear temperature decrease derived from the lapse rate $\left(T_{\text {lin }}\right)$. This was done by superimposing a time series of temperature fluctuations measured at the JFJ upon the linear temperature trajectory along which the model was run (see solid black line in Fig. 2). The time series of fluctuations was chosen to be simply that which was measured at the JFJ during the time taken for the air parcel to ascend from the point where the model was initialized (indicated in Fig. 2 with $\mathrm{RH}=90 \%$ ), to the JFJ (indicated in Fig. 2 with JFJ). The relative vertical fluctuation calculated from the measured wind field at the JFJ $\left(w^{\prime}\right)$ at time $t$ was retrieved as follows:

$w^{\prime}(t)=w_{\text {act }}^{\text {meas }}(t)-(a+b t)$,

where $a$ and $b$ are the $y$ intercept and the slope, respectively, from the linear regression function of $w_{\text {act }}^{\text {meas }}(t)$ for the time period from $t_{\text {start }}$ (the time at which the model was initialized) to $t_{\mathrm{JFJ}}$ (the time at which the modelled trajectory reached the JFJ). The deviation from $T_{\text {lin }}(t)$ due to the fluctuation $\left(T_{\text {turb }}^{\prime}(t)\right)$ was then calculated by multiplying $w^{\prime}(t)$ with the wet adiabatic lapse rate $\left(\Gamma_{\text {wet }}=0.65 \mathrm{~K}(100 \mathrm{~m})^{-1}\right.$. Adding 
$T_{\text {turb }}^{\prime}(t)$ to $T_{\text {lin }}(t)$ leads then to $T_{\text {turb }}(t) . T_{\text {turb }}^{\prime}(t)$ ranged from -0.8 to $1.1 \mathrm{~K}$ with a 25 th percentile of $0.01 \mathrm{~K}$, a 75 th percentile of $0.05 \mathrm{~K}$ and a median of $0.03 \mathrm{~K}$. Figure 2 shows an example of $T_{\text {turb }}$ for the model run simulated for conditions on 8 August 2011 18:20 UTC at the JFJ.

\subsubsection{Modelled updraft velocity}

As well as being estimated from measurements (see Sect. 2.1.3), the updraft velocity can be modelled ( $\left.w_{\mathrm{act}}^{\bmod }\right)$. With the ZOMM model, an initial model run was performed, and the number of simulated cloud droplets was compared with the observed number of cloud residuals at the JFJ. The cooling rate in the model was then iteratively adjusted until the simulated number of droplets was within $2 \%$ of the observed number of cloud residuals, which was considered to be sufficient for the propagation of $\mathrm{SS}_{\text {peak }}$ values.

The modelled updraft velocity, $w_{\text {act }}^{\text {mod }}$, was used for the reference model simulation (see Sect. 2.4). This parameter, $w_{\mathrm{act}}^{\mathrm{mod}}$, was then varied to investigate the sensitivity of the updraft velocity on $\mathrm{SS}_{\text {peak }}$ (see results in Sect. 3.2).

\subsubsection{Aerosol- and updraft-limited regimes}

Previous studies have found that a high $\mathrm{SS}_{\text {peak }}$ can be caused by a high updraft velocity or a low number of potential CCN (i.e. low number concentration of sufficiently large particles and/or low particle hygroscopicity). Conversely, a low $\mathrm{SS}_{\text {peak }}$ can be caused by small updraft velocity or a large number of potential CCN (i.e. high number concentration of large particles and/or high particle hygroscopicity). The study of Reutter et al. (2009) defined three different regimes depending on the ratio between the updraft velocity and the particle number concentration $\left(w / N_{\mathrm{CN}}\right)$ : (1) the aerosol-limited regime, (2) the updraft-limited regime and (3) the aerosol- and updraftsensitive regime (transitional regime). The aerosol-limited regime is characterized by a relatively high ratio of $w / N_{\mathrm{CN}}$, by a high activated fraction of aerosol particles (larger than $90 \%$ ) and the aerosol-limited regime is basically independent of $w$. The high updraft velocities lead to high $\mathrm{SS}_{\text {peak }}$ large enough to activate almost all of the particles except for the very small ones. The updraft-limited regime is characterized by a low ratio of $w / N_{\mathrm{CN}}$ (smaller than $20 \%$ ), saying that only a few particles are activated to cloud droplets due to low $\mathrm{SS}_{\text {peak }}$ values. In this regime the cloud droplet number concentration exhibits a linear dependence on $w$ and a weak dependence on the $N_{\mathrm{CN}}$. The aerosol- and updraft-sensitive regime is characterized by $w / N_{\mathrm{CN}}$ values lying between the two other regimes. Depending on $\mathrm{SS}_{\text {peak }}$, the critical dry activation diameter for $\mathrm{CCN}$ activation ranges from very low up to the maximum of the dry particle size distribution. All these regimes will be discussed in Sect. 3.2 regarding the sensitivity study of $\mathrm{SS}_{\text {peak }}$ on updraft velocity, particle size distribution and hygroscopicity. Thereby, the aerosol number concentration and size was varied by $\pm 15 \%$ to investigate the sensitivity of the aerosol- and updraft-limited regimes on $\mathrm{SS}_{\text {peak }}$ (see results in Sect. 3.2).

\subsubsection{Hygroscopicity parameter}

The hygroscopicity parameter, $\kappa$, stays rather constant over time at the Jungfraujoch at around 0.2 (Jurányi et al., 2011). To investigate the sensitivity of $\kappa$ to $\mathrm{SS}_{\text {peak }}$, a typical $\kappa$ value for an aerosol size distribution with a larger fraction of organics $(\kappa=0.1$; Dusek et al., 2010) and for a continental aerosol ( $\kappa=0.3$; Andreae and Rosenfeld, 2008; Pringle et al., 2010) was used (see results in Sect. 3.2). It is important to note, that the studies in Hammer et al. (2014a) and Hammer et al. (2014b) revealed only a small influence of the $\kappa$ value on the calculated $\mathrm{SS}_{\text {peak }}$.

\subsection{Reference simulations for sensitivity analysis}

For the sensitivity studies shown in Sects. 3.2 and 3.3.1 a set of reference model simulations was used. These reference simulations were performed using the data set measured at the JFJ during CLACE2011 as input variables. For this purpose an average, constant $\kappa$ value of 0.2 was used (Jurányi et al., 2011). For the updraft velocity, the simulated parameter $w_{\mathrm{act}}^{\mathrm{mod}}$ was used as described in Sect. 2.3.2. All output parameters of the reference model simulations are depicted with a superscript ${ }^{\text {ref }}$, as, e.g., for the effective peak supersaturation from the reference model simulation: $\mathrm{SS}_{\text {peak }}^{\text {ref }}$.

\section{Results and discussions}

The sensitivity of the $\mathrm{SS}_{\text {peak }}$ to the particle's size distribution and hygroscopicity, cooling rate of the air parcel (i.e. updraft velocity), and the temperature fluctuations with time have been investigated.

\subsection{Comparison of the estimated and the simulated updraft velocity}

The study of Hammer et al. (2014a) simulated $\mathrm{SS}_{\text {peak }}$ using $w_{\text {act }}^{\text {estim }}$ as an upper limit for the updraft velocity at the point of aerosol activation (see Sect. 2.1.3) and the same model as in this study. It was observed that $\mathrm{SS}_{\text {peak }}$ was generally overestimated for a particular $w_{\text {act }}^{\text {estim }}$ (see Fig. 3; red circles and solid black line). It was speculated that the estimated $w_{\text {act }}^{\text {estim }}$ might overestimate the true updraft velocity at cloud base due to flow convergence in the approach to the narrow gap in which the JFJ is located (see Fig. 1), or due to flow lines that do not strictly follow the terrain. Thus, in the present work, the mean updraft velocity was simulated with ZOMM, as described in Sect. 2.3.2. In Fig. 4 the ratio of the modelled mean updraft velocity ( $w_{\text {act }}^{\text {mod }}$ ) to $w_{\text {act }}^{\text {estim }}$ is shown for each model simulation. The ratios show that $w_{\text {act }}^{\text {mod }}$ is a factor of 4 (median) lower than the estimated $w_{\text {act }}^{\text {estim }}$. In Fig. 3, the red dots show data from Hammer et al. (2014a), where the effec- 


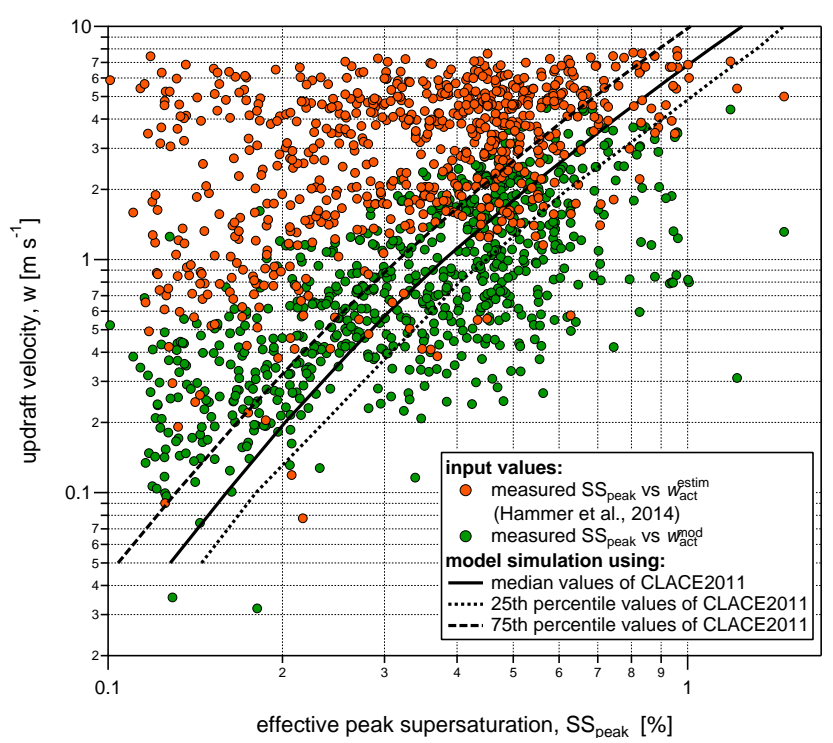

Figure 3. Each circle represents a trajectory calculation while the black lines show the trajectory calculations with the 25 th, median and 75th values of the whole campaign given in Table 2 . The relationship between the retrieved updraft velocity ( $w_{\text {act }}^{\text {estim }}$ ) and effective peak supersaturation ( $\mathrm{SS}_{\text {peak }}^{\text {estim }}$ ) is given in red circles while the relationship of the simulated updraft velocity at cloud base $\left(w_{\text {act }}^{\bmod }\right)$ and $\mathrm{SS}_{\text {peak }}^{\text {estim }}$ is given in green circles.

tive peak supersaturation was plotted against the estimated updraft velocity, $w_{\text {act }}^{\text {estim }}$. There, it was found that there was a very weak correlation between updraft velocity and $\mathrm{SS}_{\text {peak }}^{\text {estim }}$ (derived from measurements; see Sect. 2.1.4). The modelled data points are substantially closer to the model simulations when $w_{\text {act }}^{\text {mod }}$ (green circles) rather than $w_{\text {act }}^{\text {estim }}$ (red circles), is plotted against $\mathrm{SS}_{\text {peak }}^{\text {estim }}$ as $w_{\text {act }}^{\text {mod }}$ was calculated by constraining the model to the observed number of activated droplets, which is related to $\mathrm{SS}_{\text {peak }}$. When the model is constrained to reproduce the observed number of droplets, a lower updraft velocity is found. This then causes a better agreement between modelled and estimated $\mathrm{SS}_{\text {peak }}$, suggesting that the updraft velocity estimated from wind speed measurements at the JFJ is indeed overestimated.

The black curves in Fig. 3 represent the box model simulations of $\mathrm{SS}_{\text {peak }}^{\text {mod }}$ obtained by running the simulations for a range of constant updraft velocities. In the upper, dashed line, the aerosol size distribution was chosen so that the number and sizes of the aerosol and $\kappa$ value were representative of the 75th percentile of those observed during CLACE2011. The bottom, dashed line was calculated similarly using aerosol properties representative of the 25 th percentile, with the middle line calculated using aerosol properties representative of the median. From this, the expected effect of updraft velocity on $\mathrm{SS}_{\text {peak }}$ can be seen. The solid black line lies near the middle of the cloud of green points, and the variability of the green circles about the line is a result of the different chemi-

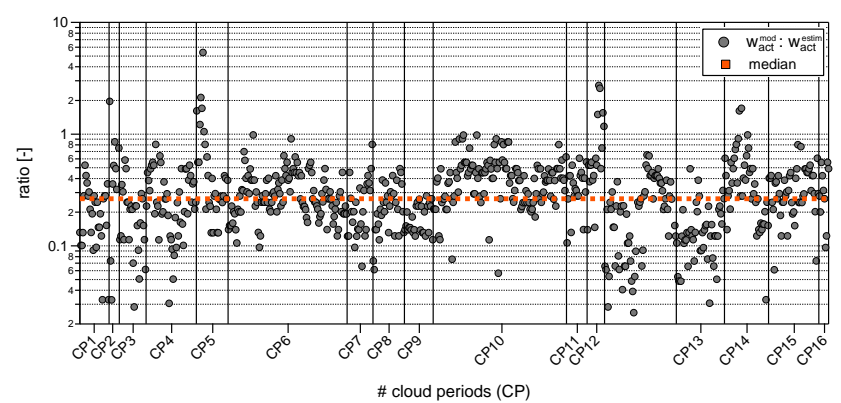

Figure 4. Ratio of the simulated updraft velocity ( $\left.w_{\text {act }}^{\bmod }\right)$ and the estimated updraft velocity at the cloud base ( $\left.w_{\text {act }}^{\text {estim }}\right)$ for each model simulation categorized for the different cloud periods (CP). The lines and the labels of $\mathrm{CP}$ serve to identify different cloud periods between which there are gaps of non-cloudy time. The orange line indicates the median ratio of $w_{\mathrm{act}}^{\mathrm{mod}}: w_{\mathrm{act}}^{\mathrm{estim}}$.

cal and physical properties of the aerosol distributions in the different model simulations. The dashed curves represent the box model simulations of $\mathrm{SS}_{\text {peak }}^{\text {mod }}$ using the 25 th and the 75 th percentiles of the aerosol properties from CLACE2011 (see values in Table 2). While the data points showing the $\mathrm{SS}_{\text {peak }}^{\text {estim }}$ values derived from measurements vs. the $w_{\text {act }}^{\text {estim }}$ values are spread across the upper left half of the plot, the relationship between $\mathrm{SS}_{\text {peak }}^{\text {mod }}$ and $w_{\text {act }}^{\text {mod }}$ appears better defined, and the points shift substantially closer towards the black line, with $39 \%$ being between the 25 th and 75 th percentile band of the values modelled with fixed aerosol size distributions. This substantial shift in the data illustrates the strong influence that the vertical wind most likely has on the $\mathrm{SS}_{\text {peak }}$.

\subsection{Influence of the updraft velocity, particle size distribution and hygroscopicity on the effective peak supersaturation}

According to previous studies, a low $\mathrm{SS}_{\text {peak }}$ can be caused by small updraft velocity or a large number of potential $\mathrm{CCN}$. Conversely, a high $\mathrm{SS}_{\text {peak }}$ can be caused by a high updraft velocity or a low number of potential CCN (see Sect. 2.3.3).

In Sect. 3.1 it was shown that $w_{\text {act }}^{\text {mod }}$ is on average a factor of 4 lower than the estimated $w_{\text {act }}^{\text {estim }}$. This difference can most likely be explained by the fact that $w_{\text {act }}^{\text {estim }}$ is an upper limit for the updraft velocity and $w_{\text {act }}^{\text {mod }}$ is based on the simulated number of cloud droplets and the number of cloud residuals at the JFJ (as described in Sect. 2.3.2). Thus, $w_{\text {act }}^{\text {mod }}$ is not an upper limit but the "true" updraft velocity at the point of aerosol activation. To investigate the sensitivity of $\mathrm{SS}_{\text {peak }}$ to the updraft velocity, the modelled value $w_{\text {act }}^{\text {mod }}$ was divided by $2\left(w_{\text {mod }}^{\text {div } 2}\right)$, divided by $5\left(w_{\text {mod }}^{\text {div } 5}\right)$, multiplied by $2\left(w_{\text {mod }}^{\text {mul }}\right)$ and $5\left(w_{\text {mod }}^{\text {mul5 }}\right)$. The ratio 5 describes the maximum deviation from the mean value of $w_{\text {act }}^{\text {mod }}$ and the ratio 2 is given from the 75 th and 25th percentile of $w_{\text {act }}^{\text {mod }}$, which are about a factor of 2 from the mean value. Figure 5 shows the ratio of $\mathrm{SS}_{\text {peak }}\left(w_{\text {mod }}^{\text {mulx }}\right)$ using the modified updraft velocities as input 
Table 2. Box model input parameters used for Fig. 3. The 25th, median and 75th percentile of the dry aerosol number size distribution were calculated binwise. The median and 75 th percentile of the dry aerosol number size distribution resulted in a bimodal distribution and thus two modes are given.

\begin{tabular}{llrrr}
\hline Measured parameter(s) & $\begin{array}{r}\text { 25th } \\
\text { percentiles }\end{array}$ & median & $\begin{array}{r}75 \text { th } \\
\text { percentiles }\end{array}$ \\
\hline Hygroscopicity parameter [-] & 0.19 & 0.26 & 0.37 \\
Dry aerosol number & 50 & 51,131 & 46,136 \\
Size distribution & modes $[\mathrm{nm}]^{*}$ FWHM $^{*}[\mathrm{~nm}]$ & 102 & 179 & 200 \\
Temperature at the JFJ [K] & 270 & 272 & 273 \\
Pressure at the JFJ [hPa] & 659.6 & 660.5 & 663.2 \\
Total water content $\left[\mathrm{mg} \mathrm{m}^{-3}\right]$ & 4110 & 4750 & 5200 \\
\hline
\end{tabular}

* Full width at half maximum.

parameters to the $\mathrm{SS}_{\mathrm{peak}}^{\mathrm{ref}}$ using the input parameter $w_{\text {act }}^{\bmod }$. All symbols are colour coded to show the number concentration in the size range of 96 (median dry activation diameter for CLACE2011) and $500 \mathrm{~nm}$ (upper limit of the SMPS). This value was used as an estimate for the potential CCN number concentration. It was found that using $w_{\text {mod }}^{\text {div } 2}$ as input parameter, $\mathrm{SS}_{\text {peak }}^{\text {ref }}$ is lowered on average by $25 \%$ and using $w_{\text {act }}^{\text {div5 }}$ as input parameter lowers $\mathrm{SS}_{\text {peak }}^{\text {ref }}$ on average by $50 \%$. Using $w_{\text {mod }}^{\text {mul2 }}$ as input parameter the $\mathrm{SS}_{\text {peak }}^{\text {ref }}$ is raised by $38 \%$ and with $w_{\text {mod }}^{\text {mul5 }}$ the $\mathrm{SS}_{\text {peak }}$ is on average a factor of 2 larger compared to using $w^{\text {ref }}$ (i.e. $w_{\text {act }}^{\text {mod }}$ ) as input parameter. Therefore, the relative influence of small and large changes in the updraft velocity is similar. Furthermore, an increase of the influence of $w_{\text {act }}^{\text {mod }}$ from low to high $\mathrm{SS}_{\text {peak }}^{\text {ref }}$ on $\mathrm{SS}_{\text {peak }}$ was observed. Low $\mathrm{SS}_{\text {peak }}$ values are less affected by the updraft velocity because for low $\mathrm{SS}_{\text {peak }}$ values $w_{\text {act }}^{\text {mod }}$ is already relatively low and therefore the absolute difference in $w_{\text {act }}^{\text {mod }}$ due to a division by 2 or 5 is rather small and the rate of increase in saturation will not change substantially. Comparable to the aerosol-limited regime (Reutter et al., 2009), Fig. 5 shows that the effect of changes in $w_{\text {act }}$ is slightly larger when the potential $\mathrm{CCN}$ number concentration is lower. Thus, the ratio of $w / N_{\mathrm{CN}}$ at these low $\mathrm{SS}_{\text {peak }}$ values is relatively low (at about 0.003 ) and is increasing with an increase in $\mathrm{SS}_{\text {peak }}^{\text {ref }}$ (up to about 0.03 ). This corresponds well with the results presented by Chuang (2006), and Feingold et al. (2003), who both found that under more polluted conditions, the characteristics of the droplet distribution are more sensitive to changes in the updraft velocity. In addition, the sensitivity of the peak supersaturation to a doubling (or increase by a factor of 5) in vertical wind velocity is slightly greater than the sensitivity to the corresponding decrease. This is similar to the findings of Partridge et al. (2012) for cloud droplet number concentration.

In Sect. 2 it is described that the topography at the JFJ defines two main wind directions, NW and SE wind. The variability of the particle number concentration as well as the particle size is expected to be on the same order of magni-

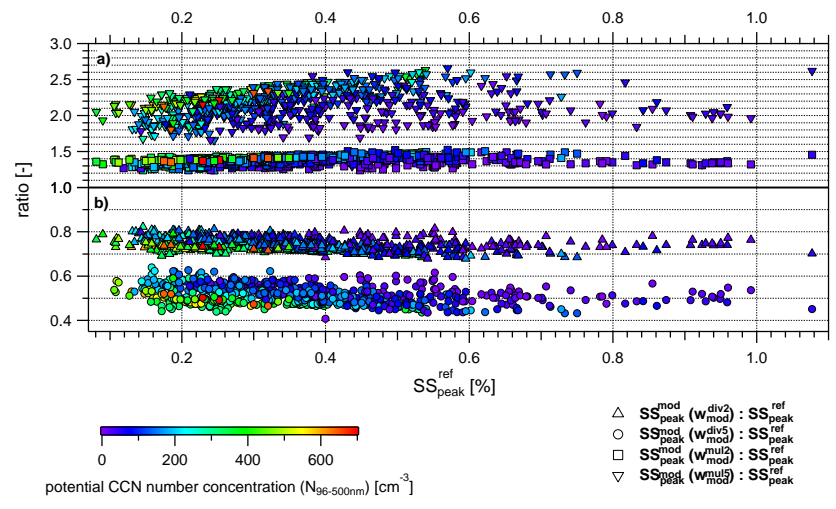

Figure 5. Ratio of modelled effective peak supersaturations using two different data sets of updraft velocities as input parameter: once divided and multiplied by $2\left(w_{\text {act }}^{\text {div } 2}, w_{\text {act }}^{\text {mul2 }}\right)$ and once divided and multiplied by 5 ( $\left.w_{\text {act }}^{\text {div } 5}, w_{\text {act }}^{\text {mul5 }}\right)$ to the reference updraft velocities $\left(w^{\text {ref }}\right)$. The points are colour coded to show the number concentration of particles in the size range of $96 \mathrm{~nm}$ (median dry activation diameter of CLACE2011) to $500 \mathrm{~nm}$ (upper limit of the SMPS). This is considered to be the potential CCN number concentration.

tude as the difference between NW and SE wind case. The dry number size distributions for the SE wind case during CLACE2011 showed on average $15 \%$ higher particle number concentration and $15 \%$ larger particles than when the wind came from the NW. To assess the sensitivity of $\mathrm{SS}_{\text {peak }}^{\text {ref }}$ to the dry particle number size distribution, the measured particle number size distribution was used as an input for the model simulations applying a $15 \%$ higher and lower particle number concentration and a $15 \%$ increase and decrease in diameter across all size bins, respectively (see Fig. 6). The effects of changing the particle number size distribution and the particle number concentration were investigated separately. An increase in the size of the particles or an increase in the number concentration leads to a decrease in the $\mathrm{SS}_{\text {peak }}$, relative to the $\mathrm{SS}_{\mathrm{peak}}^{\mathrm{ref}}$, due to earlier activation of more particles. Similarly, smaller particles or lower number concentrations lead to an increased $\mathrm{SS}_{\text {peak }}$. It is interesting to note 


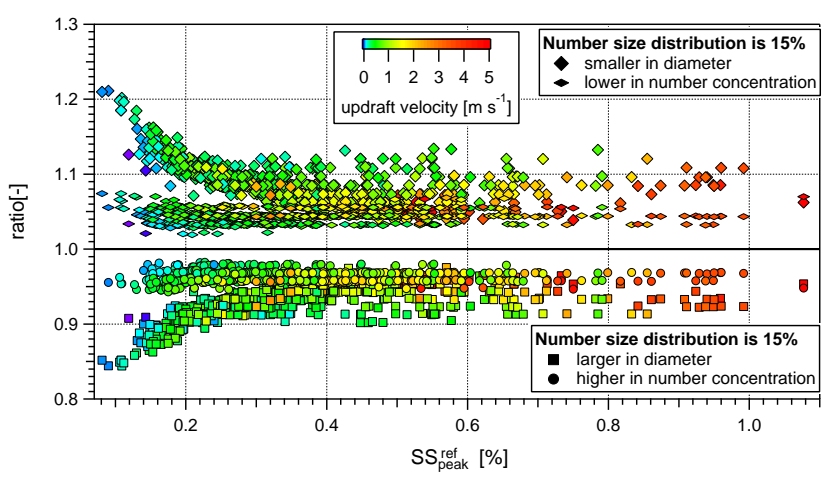

Figure 6. Ratio $\mathrm{SS}_{\text {peak }}$ : $\mathrm{SS}_{\text {peak }}^{\text {ref }}$ using: $15 \%$ higher (circles) and lower (flat diamonds) particle number concentration compared to the measured one, and $15 \%$ larger (squares) and smaller (diamonds) particles compared to the measured size distribution. All symbols are colour coded to show the modelled updraft velocities.

that by changing the number concentration, the ratio between $\mathrm{SS}_{\text {peak }}$ and $\mathrm{SS}_{\text {peak }}^{\text {ref }}$ is modified by a fairly constant amount (approximately a $5 \%$ increase for lower number concentrations and a $5 \%$ decrease for higher number concentrations). Changing the diameter of the aerosol however, results in a greater change in $\mathrm{SS}_{\text {peak }}$ for points where $\mathrm{SS}_{\text {peak }}^{\text {ref }}$ is low (left hand side of Fig. 6). As shown by the colour coding, points with low $\mathrm{SS}_{\text {peak }}^{\text {ref }}$ were generally also those where the updraft velocity was smaller. Thus at low updraft velocity, a change in the aerosol size has a greater effect on the $\mathrm{SS}_{\text {peak }}$ reached than at higher updraft velocity. This is because at low updraft velocities, the activated particles have more time to deplete the gas phase, and the $\mathrm{SS}_{\text {peak }}$ that is reached will be that required to activate only the largest particles. Any change in the size of the largest particles will translate directly into a change in the $\mathrm{SS}_{\text {peak }}$. At higher updraft velocities however, a higher $\mathrm{SS}_{\text {peak }}$ is achieved, and more of the particle size distribution is activated. Thus the $\mathrm{SS}_{\text {peak }}$ reached is less sensitive to the size of the largest particles. Changing the number of the particles on the other hand does not affect the critical saturation needed to activate the largest particles, but rather influences just the condensation sink once the critical saturation has been exceeded (Rogers and Yau, 1989). Therefore the effect is relatively constant across the range of $\mathrm{SS}_{\text {peak }}^{\text {ref }}$.

Another aerosol parameter influencing $\mathrm{SS}_{\text {peak }}$ is the hygroscopicity parameter of the dry particles, $\kappa$ (Petters and Kreidenweis, 2007). At the Jungfraujoch, it stays rather constant over time (Jurányi et al., 2011; Hammer et al., 2014a) at $\kappa \approx 0.2$. To look into the sensitivity of $\mathrm{SS}_{\text {peak }}$ to $\kappa$, a typical $\kappa$ value for an aerosol size distribution with a larger fraction of organics ( $\kappa=0.1$; Dusek et al., 2010) and for a continental aerosol $(\kappa=0.3$; Andreae and Rosenfeld, 2008; Pringle et al., 2010) was used as input for the model simulation. For the reference model simulation a $\kappa=0.2$ was used as input. Applying the aerosol size distribution with $\kappa=0.3$ as input for the model simulation results in lower $\mathrm{SS}_{\text {peak }}$ val-

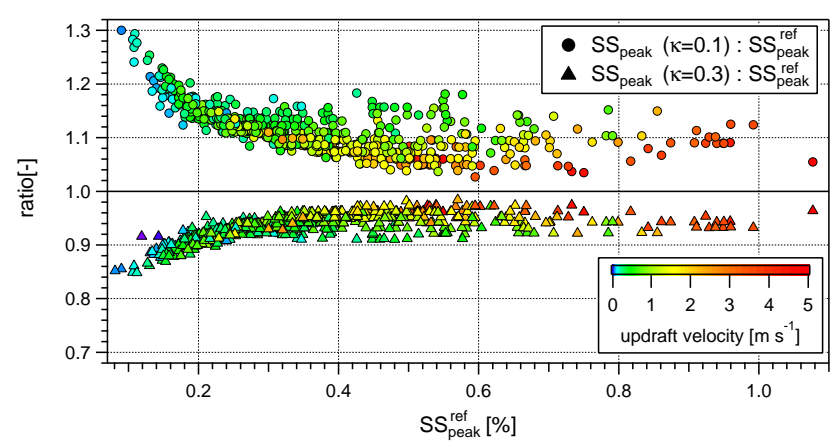

Figure 7. Ratio of effective peak supersaturation values using either a hygroscopicity value of $\kappa=0.1$ or 0.3 to the effective peak supersaturation when using the median hygroscopicity parameter measured at the Jungfraujoch of $\kappa=0.2$. The points of the data sets are colour coded to show the modelled updraft velocities.

ues compared to the reference size distribution $\left(\mathrm{SS}_{\text {peak }}^{\text {ref }}\right.$; see Fig. 7). On average the $\mathrm{SS}_{\text {peak }}$ is lowered by $6 \%$, however, for smaller $S_{\text {peak }}^{\text {ref }}$ the effect of a larger $\kappa$ value is stronger and lowers the $\mathrm{SS}_{\text {peak }}$ up to $15 \%$. The model simulations using a $\kappa$ value of 0.1 show on average $11 \%$ higher $\mathrm{SS}_{\text {peak }}$ values compared to the reference model simulation, whereas the maximum difference lies at $30 \%$. The larger increase of ratios of $\mathrm{SS}_{\text {peak }}(\kappa=0.1): \mathrm{SS}_{\text {peak }}^{\text {ref }}$ compared to the decrease for $\mathrm{SS}_{\text {peak }}(\kappa=0.3): \mathrm{SS}_{\text {peak }}^{\text {ref }}$ can be explained by the fact that a lower particle hygroscopicity results in a lower condensation of water vapour onto the particles and thus particles reach the size where the Kelvin term of the Köhler equation (Petters and Kreidenweis, 2007) becomes more important than the Raoult term and where particles activate to cloud droplets at larger sizes compared to higher particle hygroscopicity. The stronger influence of $\kappa$ on small $\mathrm{SS}_{\text {peak }}$ values can be explained by the same reason as for the smaller/larger particle number concentration: at the small updraft velocities associated with small $\mathrm{SS}_{\text {peak }}$ (see Fig. 7), the critical saturation at which the largest particles activate plays a more important role in determining the final $\mathrm{SS}_{\text {peak }}$ than it does at higher updraft velocities. The changes in $\kappa$ result in changes in this critical saturation, therefore the changes in $\kappa$ have a larger effect at low $\mathrm{SS}_{\text {peak }}^{\text {ref }}$.

\subsection{Turbulence estimations and its influence on the effective peak supersaturation}

\subsubsection{Measured turbulence}

Turbulence is often present before cloud formation and within clouds. To address the influence of turbulence on the cloud activation, i.e. on the effective peak supersaturation, the linear cooling rate was modulated with the fluctuations obtained by an ultrasonic anemometer (Metek USA-1) that was located close to the other instruments at the site as described in Sect. 2.3.1. Figure 8 shows the ratio of $\mathrm{SS}_{\text {peak }}^{\text {fluc } x}$ 


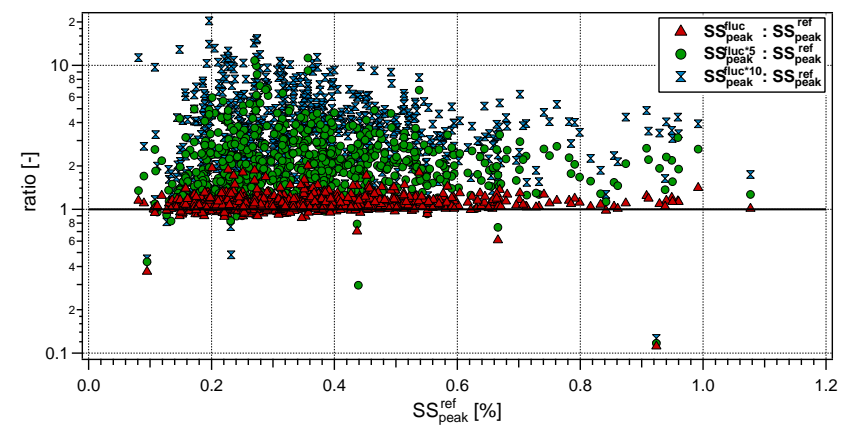

Figure 8. Ratio of modelled effective peak supersaturations applying small-scale fluctuations (obtained from the ultrasonic anemometer measurements) to the cooling rate, to the $\mathrm{SS}_{\text {peak }}^{\text {ref }}$. The small-scale fluctuations are multiplied by 1 ( $\mathrm{SS}_{\text {peak }}^{\text {fluc }}$; red triangles),

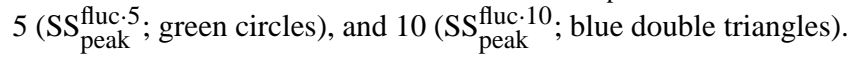

modelled applying the real-time fluctuations with a factor $(x)$ to the cooling rate vs. $\mathrm{SS}_{\text {peak }}^{\text {ref }}$ using a linear cooling rate (reference model simulation). It was assumed that each particle experienced the same real-time fluctuations. Figure 8 shows that with stronger small-scale fluctuations (i.e. a larger $x$ added to the fluctuation) the $\mathrm{SS}_{\text {peak }}$ increases significantly: applying the real-time fluctuation to the cooling rate raises the $\mathrm{SS}_{\text {peak }}$ by $\sim 8 \%$ (shown in Fig. 8 with the ratio of $\mathrm{SS}_{\text {peak }}^{\text {fluc }}$ : $\mathrm{SS}_{\text {peak }}^{\text {ref }}$ ). Multiplying the small-scale fluctuation added to the cooling rate by a factor of 5 increases the $\mathrm{SS}_{\text {peak }}$ by $\sim 87 \%$ and multiplying the fluctuations by 10 increases the $\mathrm{SS}_{\text {peak }}$ by a factor of $\sim 3.22$ (see green and blue triangles in Fig. 8, respectively). The factors 5 and 10 result in a similar range of temperature amplitudes used for the sinus curve simulations described in Sect. 3.3.2.

The evaluation of the applied real-time fluctuation to the linear cooling rate revealed a dependence of the ratios of modelled effective peak supersaturations applying smallscale fluctuations on $\mathrm{SS}_{\text {peak }}^{\text {ref }}$. There is a maximum of the ratios at $\mathrm{SS}_{\text {peak }}^{\text {ref }}$ between $0.2-0.4 \%$. The smaller ratios at higher $\mathrm{SS}_{\text {peak }}^{\text {ref }} \geq 0.2 \%$ are likely because fluctuations added to high cooling rates have a smaller relative influence on the cooling rate at the point of aerosol activation (updraft-limited regime; Reutter et al., 2009) than small-scale temperature fluctuations added to a small linear cooling rate. The reason for the smaller influence of the fluctuations in the air parcel for low $\mathrm{SS}_{\text {peak }}^{\text {ref }} \lesssim 0.2 \%$ is likely due to the competition between the influence of cooling rates and aerosol properties (aerosol-limited regime; Reutter et al., 2009). Aerosol properties such as hygroscopicity, number and size are more important at lower cooling rates and thus lead to this maximum of the ratios $\mathrm{SS}_{\text {peak }}^{\text {fluc. } x}: \mathrm{SS}_{\text {peak }}^{\text {ref }}$ for $0.2 \% \lesssim \mathrm{SS}_{\text {peak }}^{\text {ref }} \lesssim 0.4 \%$. Nevertheless, there is also a spread of the ratio at a given $\mathrm{SS}_{\text {peak }}^{\text {ref }}$. This is explained by the variable nature of the temperature fluctuations - at the point where aerosol activation

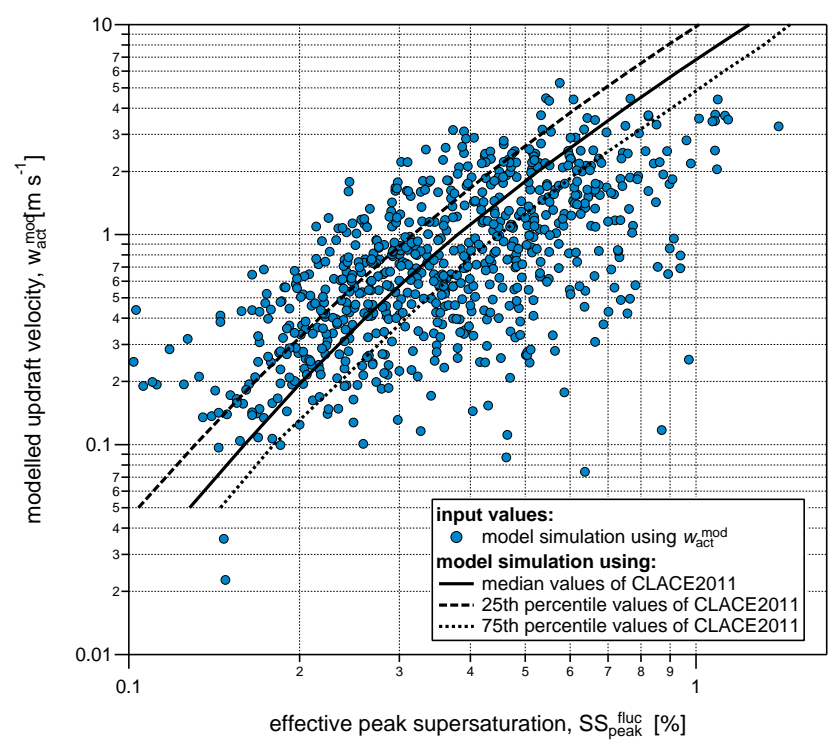

Figure 9. Same as Fig. 3 but the relationship between the modelled updraft velocity ( $\left.w_{\text {act }}^{\text {mod }}\right)$ and effective peak supersaturation taking into account the small-scale fluctuations ( $\left.\mathrm{SS}_{\text {peak }}^{\text {fluc }}\right)$.

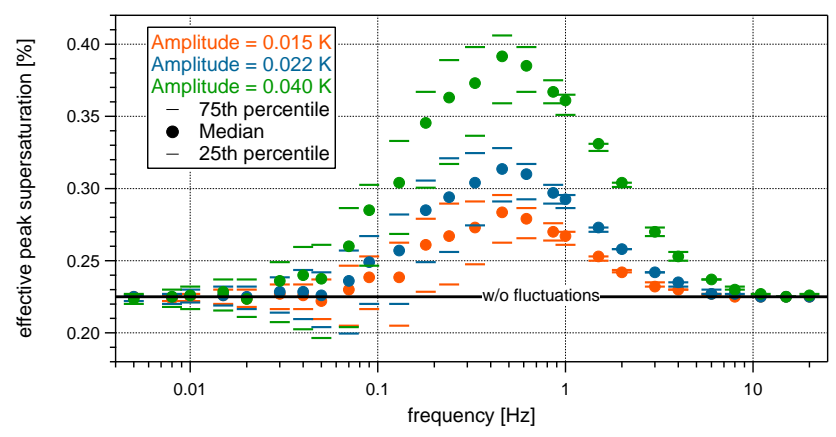

Figure 10. Dependency of the modelled effective peak supersaturations applying simulated small-scale fluctuations $\left(\mathrm{SS}_{\text {peak }}^{\text {fluc,sin }}\right)$ to the cooling rate on the frequency. The applied small-scale fluctuation were obtained with a sinus function using three different amplitudes $A=0.015$ (red), 0.022 (blue) and $0.04 \mathrm{~K}$ (green), several frequencies in the range from 0.05 to $20 \mathrm{~Hz}$ and phases from 0 to $360^{\circ}$ with $18^{\circ}$ steps. The circles indicate the median values, while the bars show the 25 th and 75 th percentiles.

occurs, the cooling rate will sometimes be greatly modified by the temperature fluctuation, in some cases it will be rather close to the average cooling rate. In the latter case, the $\mathrm{SS}_{\text {peak }}$ from the simulation including fluctuations will be close to the $\mathrm{SS}_{\text {peak }}$ calculated from the reference simulation.

Figure 3 showed that for small $w_{\text {act }}^{\text {mod }}$ the model was slightly underestimating the $\mathrm{SS}_{\text {peak }}$. However, including small-scale fluctuations slightly improves the $\mathrm{SS}_{\text {peak }}^{\text {fluc }}-w_{\text {act }}^{\text {mod }}$ relationship at lower updraft velocities as can be seen in Fig. 9. At updrafts of 0.1 to $5 \mathrm{~s}^{-1}$, the $\mathrm{SS}_{\text {peak }}^{\text {fluc }}$ to $w_{\text {act }}^{\text {mod }}$ relationship is improved slightly, with $44 \%$ of the points ly- 


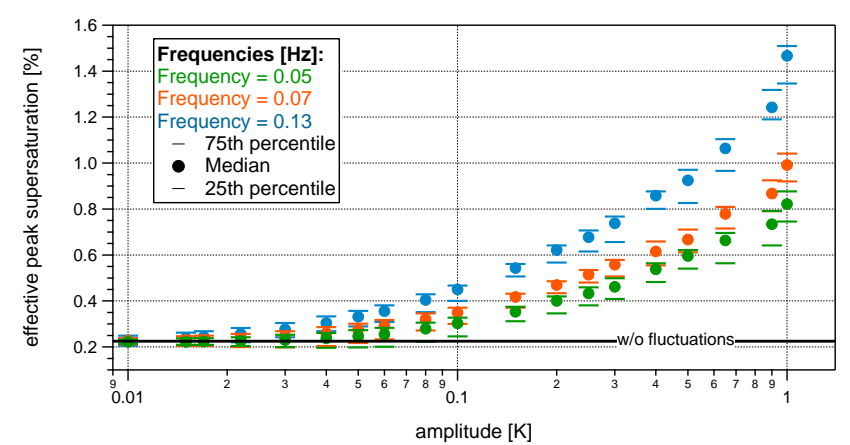

Figure 11. Dependency of the modelled effective peak supersaturations applying simulated small-scale fluctuations $\left(\mathrm{SS}_{\text {peak }}^{\text {fluc,sin }}\right)$ to the cooling rate on the amplitude. The applied small-scale fluctuation were obtained with a sinus function using three different frequencies $f=0.05$ (green), 0.07 (red) and $0.13 \mathrm{~Hz}$ (blue), several amplitudes in the range from 0.01 to $1.5 \mathrm{~K}$ and phases from 0 to $360^{\circ}$ with $18^{\circ}$ steps. The circles indicate the median values, while the bars show the 25 th and 75 th percentiles.

ing within the range of the 25-75th percentile of the measured values, compared with $40 \%$ when fluctuations are not included.

\subsubsection{Sinus curve simulations of the effective peak supersaturation}

Figure 10 shows the dependency of $\mathrm{SS}_{\text {peak }}$ on simulated small-scale fluctuations added to the cooling rate using a certain frequency $(f)$, amplitude $(A)$ and phase $(\phi)$. Three different amplitudes $(A=0.015,0.022$ and $0.04 \mathrm{~K})$ were used to simulate the small-scale fluctuations. The applied frequencies are in the range of 0.05 to $20 \mathrm{~Hz}$. The variability on the $y$ axis per $f$ is given by the different phases of the sinus functions. They are in the range of 0 to $360^{\circ}$ with $18^{\circ}$ steps. Independent of the amplitude, the influence of the frequency on $\mathrm{SS}_{\text {peak }}^{\text {fluc,sin }}$ shows a maximum at $f=0.46 \mathrm{~Hz}$. Thus, the influence of $f<0.46$ on $\mathrm{SS}_{\text {peak }}$ is decreasing since $f$ is too small to affect the cooling rate. For $f>0.46$, the influence of $f$ on $\mathrm{SS}_{\text {peak }}^{\text {fluc,sin }}$ decreases since the fluctuation is faster than the time required for significant droplet growth. Likely for the same reason the range of $\mathrm{SS}_{\text {peak }}^{\text {fluc,sin }}$ (25th and 75 th percentiles) implied by the different phases is decreasing after the maximum of $f=0.46 \mathrm{~Hz}$. It was also found that larger amplitudes imply a larger range of $f$ affecting the $\mathrm{SS}_{\text {peak }}^{\text {fluc,sin }}$ as seen in Fig. 10. Furthermore, an increase in amplitude reveals an exponential increase in $\mathrm{SS}_{\text {peak }}^{\text {fluc,sin }}$ value (see Fig. 11).

Several combinations of amplitudes and frequencies for sinus functions were found that could represent the median small-scale fluctuations in the vicinity of the JFJ. Figure 12 shows the relationship of the modelled $\mathrm{SS}_{\text {peak }}$ applying simulated small-scale fluctuations to the cooling rate $\left(\mathrm{SS}_{\text {peak }}^{\text {fluc,sin }}\right)$ and $\mathrm{SS}_{\text {peak }}^{\text {fluc }}$. The simulation of the small-scale fluctuations

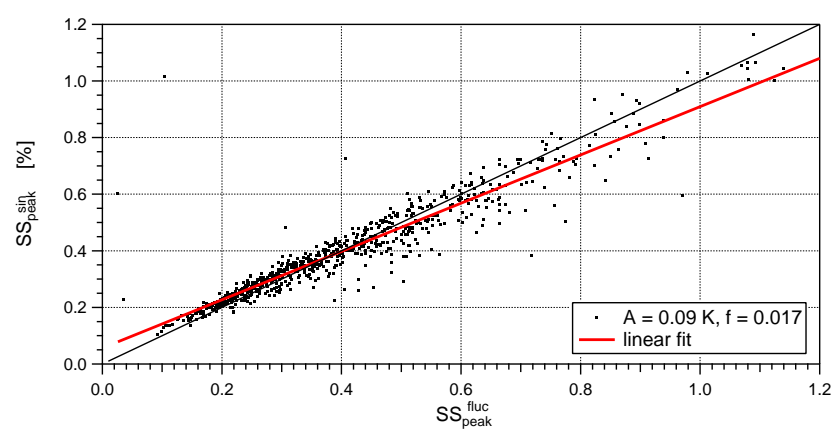

Figure 12. Modelled effective peak supersaturations applying simulated small-scale fluctuations ( $\mathrm{SS}_{\text {peak }}^{\text {fluc,sin }}$ obtained with a sinus function using an amplitude $A=0.022 \mathrm{~K}$ and a frequency $f=$ $0.24 \mathrm{~s}^{-1}$ ) to the cooling rate vs. the one applying small-scale fluctuations obtained from the ultrasonic anemometer measurements $\left(\mathrm{SS}_{\text {peak }}^{\text {fluc }}\right)$. The black line indicates the $1: 1$ line and the red line shows the linear fit.

for the cooling rate was done using the following example: $A=0.24 \mathrm{~K}$, frequency $f=0.022 \mathrm{~s}^{-1}$. The good linear correlation (slope $=0.85$, intercept $=0.06, r^{2}=0.88$ ) indicates that the combination of this amplitude and frequency is able to simulate the median small-scale fluctuations in the vicinity of the JFJ.

\section{Conclusions}

A sensitivity analysis was performed for the cloud activation at the high-alpine research station Jungfraujoch in Switzerland. The Zurich optical and microphysical model (ZOMM) was used to simulate the effective peak supersaturation within the clouds using a set of input parameters, representative of the ambient air and aerosol properties at the JFJ during CLACE2011. ZOMM is an air parcel model, and as such, does not simulate processes such as sedimentation of particles and mixing of air masses. As pointed out by Grabowski and Wang (2013) and references therein, subjecting all particles or droplets to the same temperature fluctuations, as done in this study, does not fully represent the processes of turbulent or gravitation mixing of droplets which may lead to broadening of the droplet size distributions. ZOMM calculates the flux of water to and from aerosol and droplets at $\mathrm{RH}$ above $99 \%$, while assuming equilibrium with the gas phase at lower $\mathrm{RH}$. There is no direct coupling between the latent heat release of the droplets and the parcel heat budget, although the latent heat release is taken into account when calculating the temperature trajectories used to run the model.

The analysis shows that $\mathrm{SS}_{\text {peak }}$ depends mainly on the updraft velocity, and not the physical properties of the aerosol. However, the updraft velocity is also the most difficult parameter to measure. It was observed that reducing the modelled updraft velocity, $w_{\mathrm{act}}^{\bmod }$, by a factor of 2 lowers the 
$\mathrm{SS}_{\text {peak }}$ values on average by $25 \%$, whereas a factor of 5 lowers the $\mathrm{SS}_{\text {peak }}$ on average by $50 \%$. While multiplying $w_{\text {act }}^{\bmod }$ by a factor of 2 and 5 , increases the $\mathrm{SS}_{\text {peak }}$ by a factor of $\sim 1.38$ and $\sim 2$, respectively. Thus, lowering or raising the updraft velocity to the same extent results in a similar influence on $\mathrm{SS}_{\text {peak }}$.

Another input parameter influencing the $\mathrm{SS}_{\text {peak }}$, is the shape of the aerosol size distribution and its hygroscopicity. The sensitivity analysis showed that representative aerosol size distributions for the JFJ are influencing $\mathrm{SS}_{\text {peak }}$ only to a small extent up to $21 \%$. It was observed that the $15 \%$ change in particle size had a stronger influence on the $\mathrm{SS}_{\text {peak }}$ values at lower updraft velocities than the $15 \%$-change in number concentration. The influence of the hygroscopicity on $\mathrm{SS}_{\text {peak }}$ was investigated by taking $\kappa=0.1$, as a typical value for a high organic fraction, and by taking $\kappa=0.3$ as a typical value for continental aerosols, as input parameter compared to the typical observed $\kappa$ at the JFJ of 0.2. The average difference to the reference simulation was only $\sim \pm 10 \%$, whereas the maximum difference goes up to $\sim$ $\pm 30 \%$. The lower $\kappa$ showed a stronger influence on $\mathrm{SS}_{\text {peak }}$ compared to the higher one.

Small-scale temperature variations are always present at cloud-formation processes. In this study the influence of small-scale variations on $\mathrm{SS}_{\text {peak }}$ was investigated by applying real-time fluctuations, measured with an ultrasonic anemometer, to the cooling rate. Although the fluctuations were measured at the JFJ, it is assumed that conditions that lead to greater fluctuations at the JFJ also lead to greater fluctuations at cloud base. Generally, it was found that small values of $\mathrm{SS}_{\text {peak }}^{\text {ref }}$ between approximately 0.2 and $0.4 \%$ are more strongly influenced by small-scale variations. The decreasing influence of the small-scale fluctuations on $\mathrm{SS}_{\text {peak }}^{\text {ref }} \gtrsim 0.4 \%$ could be explained due to the larger cooling rates which are less affected by small-scale variations. The decrease of the influence of the small-scale fluctuations on $\mathrm{SS}_{\text {peak }}^{\text {ref }} \lesssim 0.2 \%$ is likely due to the higher competition of the small cooling rates with the aerosol properties, i.e. at these low $\mathrm{SS}_{\text {peak }}^{\text {ref }}$ values the aerosol properties such as hygroscopicity, number concentration and size become more important. On average small-scale variations of temperature raise the $\mathrm{SS}_{\text {peak }}$ values to a larger extent than the other investigated parameters in this study: multiplying the real-time fluctuation by a factor of 5 increases the $\mathrm{SS}_{\text {peak }}$ by $\sim 87 \%$ and multiplying the fluctuations by 10 increases the $\mathrm{SS}_{\text {peak }}$ by a factor of $\sim 3.22 \mathrm{com}-$ pared to conditions without any small-scale fluctuations.

Simulating the small-scale fluctuations with several amplitudes, frequencies and phases revealed that independent of the amplitude, the effect of the frequency on $\mathrm{SS}_{\text {peak }}$ shows a maximum at $0.46 \mathrm{~Hz}$ (median over all phases). It was found that an increase in amplitude of the small-scale variations in the cooling rate, can significantly alter the CCN activation. Furthermore, small-scale fluctuations in the vicinity of the Jungfraujoch were simulated based on several sinus functions with combinations of amplitudes and frequencies. The amplitudes are in the range of 0.01 and $0.09 \mathrm{~K}$ and the frequencies in the range of 0.05 and $0.24 \mathrm{~s}^{-1}$.

In summary, small-scale temperature fluctuations, produced by variations in vertical wind velocity, are revealed to have the strongest effect on aerosol activation. Previous studies have also highlighted such fluctuations as having a strong effect on the number of aerosol activated, although it has not always been found to be the strongest factor influencing aerosol activation (e.g. Lance et al., 2004; Antilla et al., 2012). The aerosol number concentration and hygroscopic properties were found to be less important than the aerosol size in determining activation and peak supersaturation.

\section{Data availability}

The meteorological data used in this manuscript were provided by MeteoSwiss, the Swiss Federal Office of Meteorology and Climatology. They may be obtained via https:// gate.meteoswiss.ch/idaweb, after a registration process. The model used here, ZOMM, may be obtained by contacting Beiping Luo (beiping.luo@env.ethz.ch). Data measured during the CLACE2011 campaign are available from the authors.

Acknowledgements. We thank Martin Gysel (head of Aerosol Physics Group, Paul Scherrer Institute, Switzerland) for his very helpful discussions. We also thank the International Foundation High Altitude Research Stations Jungfraujoch and Gornergrat (HFSJG) for the opportunity to perform experiments on the Jungfraujoch. We would like to thank J. \& M. Fischer and M. \& U. Otz for taking care of our instrumentation and us at the Jungfraujoch. This work was supported by MeteoSwiss in the framework of the Global Atmosphere Watch programme, FP7 project ACTRIS (grant agreement no. 262254), BACCHUS (grant agreement no. 603445), as well as the Swiss National Science Foundation (SNSF) (grant number 200021 140663).

Edited by: B. Ervens

\section{References}

Andreae, M. O. and Rosenfeld, D.: Aerosol-cloudprecipitation interactions. Part 1. The nature and sources of cloud-active aerosols, Earth-Sci. Rev., 89, 13-41, doi:10.1016/j.earscirev.2008.03.001, 2008.

Anttila, T., Brus, D., Jaatinen, A., Hyvärinen, A.-P., Kivekäs, N., Romakkaniemi, S., Komppula, M., and Lihavainen, H.: Relationships between particles, cloud condensation nuclei and cloud droplet activation during the third Pallas Cloud Experiment, Atmos. Chem. Phys., 12, 11435-11450, doi:10.5194/acp12-11435-2012, 2012.

Boucher, O., Randall, D., Artaxo, P., Bretherton, C., Feingold, G., Forster, P., Kerminen, V.-M., Kondo, Y., Liao, H., Lohmann, U., Rasch, P., Satheesh, S. K., Sherwood, S., Stevens, B., and Zhang, X.: Cloud and aerosols, in: Climate Change 2013: The Physical Science Basis. Contribution of Working Group I to the 
Fifth Assessment Report of the Intergovernmental Panel on Climate Change, Cambridge University Press, Cambridge, UK and New York, NY, USA, 2013.

Cherian, R., Quaas, J., Salzmann, M., and Wild, M.: Pollution trends over Europe constrain global aerosol forcing as simulated by climate models, Geophys. Res. Lett., 41, 2176-2181, doi:10.1002/2013GL058715, 2014.

Chuang, P. Y.: Sensitivity of cloud condensation nuclei activation processes to kinetic parameters, Geophys. Res. Atmos., 111, D09201, doi:10.1029/2005JD006529, 2006.

Clark, T. and Hall, W. D.: A numerical experiment on stochastic condensation theory, J. Atmos. Sci., 36, 3, 470-483, 1979.

Ditas, F., Shaw, R. A., Siebert, H., Simmel, M., Wehner, B., and Wiedensohler, A.: Aerosols-cloud microphysicsthermodynamics-turbulence: evaluating supersaturation in a marine stratocumulus cloud, Atmos. Chem. Phys., 12, 2459-2468, doi:10.5194/acp-12-2459-2012, 2012.

Dufresne, J.-L., Foujols, M.-A., Denvil, S., Caubel, A., Marti, O., Aumont, O., Balkanski, Y., Bekki, S., Bellenger, H., Benshila, R., Bony, S., Bopp, L., Braconnot, P., Brockmann, P., Cadule, P., Cheruy, F., Codron, F., Cozic, A., Cugnet, D., Noblet, N., Duvel, J.-P., Ethé, C., Fairhead, L., Fichefet, T., Flavoni, S., Friedlingstein, P., Grandpeix, J.-Y., Guez, L., Guilyardi, E., Hauglustaine, D., Hourdin, F., Idelkadi, A., Ghattas, J., Joussaume, S., Kageyama, M., Krinner, G., Labetoulle, S., Lahellec, A., Lefebvre, M.-P., Lefevre, F., Levy, C., Li, Z., Lloyd, J., Lott, F., Madec, G., Mancip, M., Marchand, M., Masson, S., Meurdesoif, Y., Mignot, J., Musat, I., Parouty, S., Polcher, J., Rio, C., Schulz, M., Swingedouw, D., Szopa, S., Talandier, C., Terray, P., Viovy, N., and Vuichard, N.: Climate change projections using the IPSL-CM5 Earth System Model: from CMIP3 to CMIP5, Climate Dyn., 40, 2123-2165, doi:10.1007/s00382-0121636-1, 2013.

Dusek, U., Frank, G. P., Curtius, J., Drewnick, F., Schneider, J., Kürten, A., Rose, D., Andreae, M. O., Borrmann, S., and Pöschl, U.: Enhanced organic mass fraction and decreased hygroscopicity of cloud condensation nuclei $(\mathrm{CCN})$ during new particle formation events, Geophys. Res. Lett., 37, 1944-8007, doi:10.1029/2009GL040930, 2010.

Feingold, G., Eberhard, W. L., Veron, D. E., and Previdi, M.: First measurements of the Twomey indirect effect using ground-based remote sensors, Geophys. Res. Lett., 30, 1287, doi:10.1029/2002GL016633, 2003.

Gerber, H.: Direct measurement of suspended particulate volume concentration and far-infrared extinction coefficient with a laser-diffraction instrument, Appl. Opt., 30, 4824-4831, doi:10.1364/AO.30.004824, 1991.

Goff, J. A. and Gratch, S.: Low-pressure properties of water from -160 to 212 F, Trans. Amer. Soc. Heat. Vent. Eng., 51, 125-164, 1946.

Grabowski, W. W. and Wang, L.-P.: Growth of Cloud Droplets in a Turbulent Environment, Ann. Rev. Fluid Mech., 45, 293-324, doi:10.1146/annurev-fluid-011212-140750, 2013.

Hammer, E., Bukowiecki, N., Gysel, M., Jurányi, Z., Hoyle, C. R., Vogt, R., Baltensperger, U., and Weingartner, E.: Investigation of the effective peak supersaturation for liquid-phase clouds at the high-alpine site Jungfraujoch, Switzerland (3580 m a.s.1.), Atmos. Chem. Phys., 14, 1123-1139, doi:10.5194/acp-14-11232014, 2014.
Hammer, E., Gysel, M., Roberts, G. C., Elias, T., Hofer, J., Hoyle, C. R., Bukowiecki, N., Dupont, J.-C., Burnet, F., Baltensperger, U., and Weingartner, E.: Size-dependent particle activation properties in fog during the ParisFog 2012/13 field campaign, Atmos. Chem. Phys., 14, 10517-10533, doi:10.5194/acp14-10517-2014, 2014.

Henning, S., Weingartner, E., Schmidt, S., Wendisch, M., Gaggeler, H. W., and Baltensperger, U.: Size-dependent aerosol activation at the high-alpine site Jungfraujoch (3580 ma.s.1.), Tellus B, 54, 82-95, doi:10.1034/j.1600-0889.2002.00299.x, 2002.

Hoyle, C. R., Luo, B. P., and Peter, T.: The origin of high ice crystal number densities in cirrus clouds, J. Atmos. Sci., 62, 2568-2579, doi:10.1175/JAS3487.1, 2005.

Hoyle, C. R., Engel, I., Luo, B. P., Pitts, M. C., Poole, L. R., Grooß, J.-U., and Peter, T.: Heterogeneous formation of polar stratospheric clouds - Part 1: Nucleation of nitric acid trihydrate (NAT), Atmos. Chem. Phys., 13, 9577-9595, doi:10.5194/acp13-9577-2013, 2013.

Jones, A.: A climate model study of indirect radiative forcing by anthropogenic sulphate aerosols, Nature, 370, 450-453, 1994.

Jurányi, Z., Gysel, M., Weingartner, E., Bukowiecki, N., Kammermann, L., and Baltensperger, U.: A 17 month climatology of the cloud condensation nuclei number concentration at the high alpine site Jungfraujoch, J. Geophys. Res.-Atmos., 116, 21562202, doi:10.1029/2010JD015199, 2011.

Ketterer, C., Zieger, P., Bukowiecki, N., Collaud Coen, M., Maier, O., Ruffieux, D., and Weingartner, E.: Investigation of the planetary boundary layer in the Swiss Alps using remote sensing and in situ measurements, Bound.-Lay. Meteorol., 151, 317-334, doi:10.1007/s10546-013-9897-8, 2014.

Köhler, H.: The nucleus in and the growth of hygroscopic droplets, T. Faraday Soc., 32, 1152-1161, doi:10.1039/TF9363201152, 1936.

Kulmala, M., Rannik, U., Zapadinsky, E. L. and Celement, C. F.: The effect of saturation fluctuations on droplet growth, J. Aerosol Sci., 28, 1395-1409, 1997.

Lance, S., Nenes, A., and Rissman, T. A.: Chemical and dynamical effects on cloud droplet number: Implications for estimates of the aerosol indirect effect, J. Geophys. Res., 109, D22208, doi:10.1029/2004JD004596, 2004.

Levy, H., Horowitz, L. W., Schwarzkopf, M. D., Ming, Y., Golaz, J.C., Naik, V., and Ramaswamy, V.: The roles of aerosol direct and indirect effects in past and future climate change, J. Geophys. Res.-Atmos., 118, 4521-4532, doi:10.1002/jgrd.50192, 2013.

Luo, B. P., Voigt, C., Fueglistaler, S., and Peter, T.: Extreme NAT supersaturations in mountain wave ice PSCs: A clue to NAT formation, J. Geophys. Res., 108, 4441, doi:10.1029/2002JD003104, 2003.

Martin, G. M., Johnson, D. W., and Spice, A.: The measurement and parameterization of effective radius of droplets in warm stratocumulus clouds, J. Atmos. Sci., 51, 1823-1842, doi:10.1175/15200469(1994)051h1823:TMAPOEi2.0.CO;2, 1994.

Partridge, D. G., Vrugt, J. A., Tunved, P., Ekman, A. M. L., Struthers, H., and Sorooshian, A.: Inverse modelling of cloudaerosol interactions - Part 2: Sensitivity tests on liquid phase clouds using a Markov chain Monte Carlo based simulation approach, Atmos. Chem. Phys., 12, 2823-2847, doi:10.5194/acp12-2823-2012, 2012. 
Petters, M. D. and Kreidenweis, S. M.: A single parameter representation of hygroscopic growth and cloud condensation nucleus activity, Atmos. Chem. Phys., 7, 1961-1971, doi:10.5194/acp-71961-2007, 2007.

Politovich, M. K. and Cooper, W. A.: Variability of the Supersaturation in Cumulus Clouds, J. Atmos. Sci., 45, 1651-1664, doi:10.1175/1520-0469(1988)045<1651:VOTSIC>2.0.CO;2, 1988.

Pringle, K. J., Tost, H., Pozzer, A., Pöschl, U., and Lelieveld, J.: Global distribution of the effective aerosol hygroscopicity parameter for $\mathrm{CCN}$ activation, Atmos. Chem. Phys., 10, 52415255, doi:10.5194/acp-10-5241-2010, 2010.

Raga, G. B. and Jonas, P. R.: On the link between cloudtop radiative properties and sub-cloud aerosol concentrations, Quart. J. Roy. Meteor. Soc., 119, 1419-1425, doi:10.1002/qj.49711951410, 1993.

Reutter, P., Su, H., Trentmann, J., Simmel, M., Rose, D., Gunthe, S. S., Wernli, H., Andreae, M. O., and Pöschl, U.: Aerosol- and updraft-limited regimes of cloud droplet formation: influence of particle number, size and hygroscopicity on the activation of cloud condensation nuclei (CCN), Atmos. Chem. Phys., 9, 70677080, doi:10.5194/acp-9-7067-2009, 2009.

Roberts, G. C. and Nenes, A.: A continuous-flow streamwise thermal-gradient $\mathrm{CCN}$ chamber for atmospheric measurements, Aerosol Sci. Tech., 39, 206-221, doi:10.1080/027868290913988, 2005.
Rogers, R. and Yau, M.: A Short Course in Cloud Physics, International Series in Natural Philosophy, Butterworth Heinemann, Burlington, MA, 1989.

Spichtinger, P. and Cziczo, D.J..: Aerosol-cloud interactions - a challenge for measurements and modeling at the cutting edge of cloud-limate interactions, Environ. Res. Lett., 3, 025002, doi:10.1088/1748-9326/3/2/025002, 2008.

Wiedensohler, A., Birmili, W., Nowak, A., Sonntag, A., Weinhold, K., Merkel, M., Wehner, B., Tuch, T., Pfeifer, S., Fiebig, M., Fjäraa, A. M., Asmi, E., Sellegri, K., Depuy, R., Venzac, H., Villani, P., Laj, P., Aalto, P., Ogren, J. A., Swietlicki, E., Williams, P., Roldin, P., Quincey, P., Hüglin, C., Fierz-Schmidhauser, R., Gysel, M., Weingartner, E., Riccobono, F., Santos, S., Grüning, C., Faloon, K., Beddows, D., Harrison, R., Monahan, C., Jennings, S. G., O’Dowd, C. D., Marinoni, A., Horn, H.-G., Keck, L., Jiang, J., Scheckman, J., McMurry, P. H., Deng, Z., Zhao, C. S., Moerman, M., Henzing, B., de Leeuw, G., Löschau, G., and Bastian, S.: Mobility particle size spectrometers: harmonization of technical standards and data structure to facilitate high quality long-term observations of atmospheric particle number size distributions, Atmos. Meas. Tech., 5, 657-685, doi:10.5194/amt5-657-2012, 2012. 